\title{
Internet addiction among Indian help-seeking patients with mental health disorders
}

\author{
Nisbin $\mathrm{AK}^{1}$, Sharma $M K^{2}$ and Hallford $\mathrm{DJ}^{3 *}$ \\ ${ }^{1}$ Clinical Psychologist, Department of Clinical Psychology, NIMHANS, Bangalore-560029, Karnataka, India \\ ${ }^{2}$ Department of Clinical Psychology, SHUT Clinic, NIMHANS, Bangalore-560029, Karnataka, India \\ ${ }^{3}$ Deakin Health Postdoctoral Research Fellow, Academy of Sciences Australia-India Research Fellow School of Psychology, Deakin University, 1 Gheringhap Road, \\ Geelong, Australia
}

\begin{abstract}
Internet addiction is a pernicious behavioural disorder that has received increasingly more interest as societies become more technological. This study addressed the current lack of data in the Indian context by examining problematic internet use among individuals receiving treatment for mental health disorders. In addition, it examined specific uses of the internet that have the potential to be problematic and impact on quality of life, namely social media use and online gaming, the reasons why people used the internet, and the perceived benefits and problems it gives rise to. Almost half (44\%) of the sample reported severely dependent levels of internet addiction. Those with depressive disorders reported higher levels of internet addiction relative to other disorders. Findings regarding benefits and problems of internets use were somewhat paradoxical, whereby internet use could be both beneficial and problematic in the domain (e.g., increased and decreased social interaction). The use of screening for internet addiction, and the development of culturally-adapted treatments for Indians with mental health disorders may be indicated.
\end{abstract}

\section{Introduction}

Internet and technology use is rapidly on the rise in India. The Telecom Regulatory Authority of India recently reported that over 422 million people are actively using the internet, with sustained growth in this figure over time [1]. While access to the internet can provide significant benefits to the community, such as improved communication, access to information, and entertainment, for some people excessive and problematic use can lead to negative consequences in daily life. Specifically, symptoms of Internet addiction can include a) preoccupation with Internet activities; b) increasing tolerance; c) development of psychological dependency and withdrawal symptoms; d) inability to reduce Internet use; e) Internet use to cope with negative moods and reduce stress; and f) replacing other activities and relationships with recurrent Internet use despite awareness of the deleterious consequences [2].

Research over the last two decades has indicated that problematic internet use is correlated with poor mental health and low quality of life [3]. For example, a systematic review on problematic internet use showed that $75 \%$ of studies reported positive correlations with depressive symptoms, $57 \%$ showed positive correlations with anxiety symptoms, $100 \%$ with attention deficit hyperactivity disorder symptoms, $60 \%$ with obsessive-compulsive disorder symptoms, and $66 \%$ with hostility and aggression [4]. Using meta-analyses, Ho, et al. [5] reported that, relative to healthy controls, there were significantly higher rates of psychiatric diagnoses among those with internet addiction, including alcohol abuse (13.3\% vs. $4.3 \%)$, attention deficit and hyperactivity disorder (21.7\% vs. $8.9 \%)$, depressive disorders (26.3\% vs. $11.7 \%)$, and anxiety disorders (23.3\% vs. $10.3 \%)$. Wildt, et al. [6] reported that in a sample of 41 individuals diagnosed with internet addiction, $56.4 \%$ met criteria for one personality disorder, while $28.4 \%$ met criteria for at least two. Further, a recent case-control study of patients with depressive disorders showed high rates of internet addiction (36\%) [7]. Given that a meta-analysis on the global prevalence of internet addiction has estimated average rates to be around 6\%, internet addiction appears likely to be significantly more prevalent in the context of psychiatric illness [3].

In the Indian context, studies have shown the prevalence of internet addiction to be $1.3 \%$ in the general population [8]. Higher rates of $11.8 \%, 8.8 \%$, and $8 \%$ have been reported in college populations, and lower rates in adolescence (0.7\%) [9-12]. Two studies using samples of health professionals in India have been reported, with one showing the prevalence of severe internet addiction among dental students $(2.3 \%)$ to be higher relative to other medical students (1.2\%), and the other showing a prevalence rate of $9.5 \%$ of internet addiction among medical college students collectively [13]. Inconsistencies across studies in how internet addiction was measured may account for at least some of this variation.

Regarding psychiatric comorbidity, some studies in India have reported higher rates of depression and anxiety symptoms among those with problematic internet use, however, to the authors' knowledge, only two studies to date have examined internet addiction within defined psychiatric populations in India $[9,12,13]$. In a case study report, two cases of internet-addicted young males in a psychiatric setting were described [14]. The remaining study surveyed 75 psychiatric patients for internet addiction and related problematic use of mobile

${ }^{\star}$ Correspondence to: David Hallford, Clinical Psychologist, MAPS, Deakin Health Postdoctoral Research Fellow,Academy of Sciences Australia-India Research Fellow School of Psychology, Deakin University, 1 Gheringhap Road, Geelong, Australia, Tel: +61 421763 436; E-mail: david.hallford@deakin.edu.au

Key words: internet addiction, psychiatric diagnosis, mental health

Received: January 21, 2019; Accepted: February 08, 2019; Published: February 11,2019 
phones and videogames [15]. The results showed significantly higher prevalence rates than those found in the general population, with $16 \%$ of the sample reporting at least moderate severity of internet addiction, and $28 \%$ at least mild difficulty. The frequency of addiction for mobile videogames was also high at $14.7 \%$. On examining participants' reasons for internet use, $58.7 \%$ of the sample reported using it and related-technology to "feel good", with $14.7 \%$ using it to avoid negative emotions, and $2.7 \%$ to directly cope with a situation.

The presence of internet addiction in psychiatric populations appears to be high, however, there is a current lack of epidemiological data in India. While internet use may have some adaptive functions in terms of emotional regulation and social connectedness, excessive use in general appears to be related to an overall lower quality of life [3]. Aside from warranting treatment it its own right, the presence of internet addiction may complicate co-morbid psychiatric issues that patients may be presenting for as their primary complaint. The current study aimed to examine problematic internet use among individuals receiving treatment for mental health disorders. In addition, the study examined specific uses of the internet that have the potential to be problematic and impact on quality of life, namely social media use and online gaming $[16,17]$. Lastly, to understand the motivations and consequences of use, we also surveyed the reasons why people used the internet, and the perceived benefits and problems it gives rise to.

\section{Methods}

\section{Participants}

The sample comprised 92 participants recruited from the National Institute of Mental Health and Neurosciences (NIMHANS) in Bangalore, India. Over the course of three months, all files at one of the Adult Psychiatry Units and one of the Center for Addiction Medicine Units were monitored for potential participants. Inclusion criteria was 1) a mental health problem, defined as having an ICD-10 diagnosed depressive disorder $(n=37,40.2 \%)$, anxiety or impulse control disorder $(n=27,29.3 \%)$, or a substance use disorder $(n=28,30.4 \%), 2)$ aged 18 and above, and 3) English speaking and literate. Exclusion criteria were participants with psychotic disorders, neurological disorders, intellectual disability, or other medical problems which may have interfered with taking the assessment. The majority were receiving pharmacological treatment $(69.6 \%)$, while around a third were engaged in psychological intervention (30.4\%). Regarding severity, $21.7 \%$ were classified as severely symptomatic, $45.7 \%$ as moderate, and $32.6 \%$ as mild. The average duration of illness was 3.1 years $(S D=1.5)$.

The age range was 18 to 38 years $(M=25.7, S D=6)$, and $85.9 \%$ of the sample were male. Regarding the highest level of education, $18.5 \%$ had post-graduate qualifications, $22.8 \%$ graduate, $31.5 \%$ higher secondary, 23.\% secondary, and 3.3\% were below secondary. Most of the sample were working, either in a private $(48.9 \%)$ or government job (7.6\%) whereas $35.9 \%$ were studying, and $7.5 \%$ were neither employed nor studying. A total of $60 \%$ reported being single, $30.4 \%$ married, and $4.3 \%$ separated. The majority identified as Hindu (46.7\%), with the remainder Muslim (28.3\%) and Christian (25\%).

\section{Measures}

As part of the survey packet, the participants completed demographic questions, questions relating to the types of electronic devices used, frequency of internet use, the purposes of engaging in internet use, the perceived benefits and problems of internet use, strategies attempted to reduce internet use, and the following questionnaires
The Internet Addiction Test [18]. The IAT is one of the most utilized instruments for assessing internet addiction. It consists of 20 self-report items covering the degree to which their internet use affects daily life. The items assess the salience of internet use, excessive use, neglecting work, anticipation, lack of control and neglecting social life. Participants respond to items using a 6-point Likert scale ranging from 0 (Does Not Apply) to 5 (Always). The responses were summed, with total scores of 31 to 49 indicative of a mild level of Internet addiction, 50 to 79 a moderate addiction, and scores of 80 to 100 a severe dependence, as per convention. The IAT has shown good concurrent validity, internal consistency and test-retest reliability [19]. The internal reliability in this sample was excellent (Cronbach's $\alpha=.97$ )

Bergen Facebook Addiction Scale (BFAS) [20]. This 6-item selfreport scale is designed to assess addiction to the social networking site Facebook. The items assess how much the activity dominates their thinking and behavior, modifies or improves mood, whether increasing amounts are required to achieve previous effects, the occurrence of unpleasant feelings when the activity is discontinued or suddenly reduced, whether it causes conflicts in relationships, work/education or other, and a tendency to revert to earlier patterns of the activity after abstinence or control. Responses are given on a 5-point Likert scale ranging from 1 (Very Rarely) to 5 (Very Often). Scores of 'often' or 'very often' on at least 4 of the 6 items indicate an addiction to Facebook. The BFAS has demonstrated good test-retest reliability, convergent validity and internal consistency [20]. The internal reliability in this sample was good (Cronbach's $\alpha=.82$ )

Problematic online gaming questionnaire short form (POGQSF) [17]. The POGQ-SF measures problematic online gaming using 12 self-report items that assess six underlying dimensions of problematic gaming: preoccupation, overuse, immersion, social isolation, interpersonal conflicts, and withdrawal. Participants use a 5-point Likert scale from 1 (Never) to 5 (Seldom), with higher scores indicating more problematic online gaming. The POGQ-SF has demonstrated good psychometric properties, and a cut-off score of 32 has been recommended to distinguish between problematic and nonproblematic online gamers [17]. Need Cronbach's alpha.

\section{Procedure}

The study was approved by the NIMHANS ethical committee prior to commencement. Over a consecutive three-month period, one of the researchers (N.A.K; a trainee clinical psychologist) identified eligible individuals through file audits. After gaining consent from the concerned treating team regarding appropriateness to take part, these individuals were approached to discuss the study and invited to participate. All participation was voluntary, and information was nonidentifiable. In an effort to reduce self-selection bias for internet-related problems, participants were advised that the study was one looking at lifestyle and patterns of behaviours. Participants were provided with an informed consent form, which was signed prior to completing the survey. No incentives were offered for participation.

\section{Results}

Almost all of the sample reported owning a smart mobile phone (97.8\%), while $60.9 \%$ owned laptops, $33.7 \%$ owned tablets, and $33.7 \%$ owned personal computers. Regarding internet use, $9.8 \%$ used the internet for less than 5 hours per day, $46.7 \%$ used it for around 5 hours, and $43.5 \%$ used it for more than 5 hours.

Table 1 presents the descriptive statistics and Spearman rank correlations between the scales used in the study. On examining their 
association with characteristics of the sample, it was observed that age did not correlate with any of the scales (all $p>0.444$ ), nor did duration of illness (all $p>0.222$ ). Severity of illness did not correlate with scores on the IAT $(p=0.306)$, nor BFAS $(p=0.699)$, however, higher severity was correlated with lower problematic online gaming scores on the POQG-SF $(r=-0.23, p=0.027)$.

Table 1 presents the prevalence of severely dependent internet addiction, Facebook addiction, and problematic online gaming. As indicated, almost half of the sample reported having levels of internet addiction regarded as severely dependent. A further $41.3 \%$ had moderate internet dependence, and $7.6 \%$ had mild dependence. A majority of the sample were over the cut-off for addictive use of Facebook, and close to half were above the cut-off for problematic online gaming.

Next, chi-square analyses were conducted to assess for sex differences amongst participants above and below the adopted cutoff scores. No differences were found between males and females for prevalence of internet addiction, $\chi^{2}(1)=0.52, p=.468$, Facebook addiction, $\chi^{2}(1)=0.41, p=0.522$, or problematic online gaming, $\chi^{2}(1)=$ $0.62, p=0.429$. We note that the low number of females in this sample likely limited the statistical power of these tests. We also assessed for differences between the diagnostic groupings. A trend was found for internet addiction, such that participants with depressive disorders were more likely to be severely addicted to the internet (51\%) relative to those with anxiety and impulse disorders $(23.5 \%)$ or substance use disorders $(25.5 \%), \chi^{2}(2)=5.5, p=0.063$. No differences were found for Facebook addition, $\chi^{2}(2)=2.4, p=0.293$, or problematic online gaming, $\chi^{2}(2)=3.1, p=0.208$.

With respect to reasons for engaging in internet use, $100 \%$ of the sample endorsed entertainment, $98.9 \%$ to gather general information, $84.8 \%$ social interaction, $68.5 \%$ for academic pursuits, $58.7 \%$ to access pornography, and $40.2 \%$ to play games.

Table 2 indicates the reported problems experienced as a result of internet use. As seen, almost all participants reported reduced sleep, while decreased social interaction, outdoor activity, and productivity, and increased absenteeism in work and school were all highly prevalent. Endorsed in less frequency were physical impacts of neck and back pain, and dryness of eyes, while two participants reported losing their job as an outcome of problematic internet use.

Table 3 indicates the perceived benefits of internet use. All participants reported it improved their general knowledge, over half reported it helped with their schooling or increasing their number of friends, and under half reported improvements in mood, earning money and increasing their energy.

Just over half the sample had tried to reduce their internet use (53.3\%), and this percentage was significantly lower in those severely dependent on internet use $\left(34.7 \%\right.$ vs. $\left.65.3 \%, \chi^{2}(1)=4.1, p=0.042\right)$. Strategies that were endorsed as having been used to reduce internet

Table 1. Descriptive Statistics and Intercorrelations for the Scales Used in the Study

\begin{tabular}{|c|c|c|c|c|c|}
\hline Variable & IAT & BFAS & POGQ-SF & Mean (SD) & $\begin{array}{c}\text { Percentage } \\
\text { Scoring over } \\
\text { the Cut-Off }\end{array}$ \\
\hline IAT & - & & & $70.1(18.5)$ & $44.6 \%$ \\
\hline BFAS & 0.07 & - & & $22.8(3.5)$ & $67.4 \%$ \\
\hline POGQ-SF & 0.06 & -0.07 & - & $32.6(18)$ & $45.7 \%$ \\
\hline
\end{tabular}

Note: BFAS $=$ Bergen Facebook Addiction Scale, IAT $=$ Internet Addiction Test, POGQ$\mathrm{SF}=$ Problematic Online Gaming Questionnaire - Short Form
Table 2. Perceived Problems Experienced from Internet Use

\begin{tabular}{|l|l|}
\hline Problems & $\begin{array}{l}\text { Percentage Experiencing This Problem } \\
\text { as a Result of Internet Use }\end{array}$ \\
\hline Reduced sleep & $92.4 \%$ \\
\hline Decreased Social Interaction & $80.4 \%$ \\
\hline Decreased Outdoor Activities & $80.4 \%$ \\
\hline $\begin{array}{l}\text { Reduced productivity in the workplace or } \\
\text { in study }\end{array}$ & $81.5 \%$ \\
\hline Absenteeism (from work or school) & $48.9 \%$ \\
\hline Neck pain & $42.4 \%$ \\
\hline Back pain & $37 \%$ \\
\hline Dryness of eyes & $25 \%$ \\
\hline Loss of job & $2.2 \%$ \\
\hline
\end{tabular}

Table 3. Perceived Benefits Experienced from Internet Use

\begin{tabular}{|l|l|}
\hline Benefits & $\begin{array}{l}\text { Percentage Experiencing This Benefit as } \\
\text { a Result of Internet Use }\end{array}$ \\
\hline Improve general knowledge & $100 \%$ \\
\hline Increased number of friends & $64.1 \%$ \\
\hline Facilitation of schoolwork & $57.6 \%$ \\
\hline Improved mood & $44.6 \%$ \\
\hline Earning money & $30.4 \%$ \\
\hline Increased energy & $23.9 \%$ \\
\hline
\end{tabular}

use were cutting off the internet connection (43.5\%), switching off technology devices (42.4\%), hanging out with friends $(29.3 \%)$ and interacting with family (14.1\%).

\section{Discussion}

The current study aimed to examine the prevalence rates of internet addiction and specific uses of the internet among a helpseeking, psychiatric population in Bangalore, India. Almost half of the patient sample scored above the cut-off on the Internet Addiction Test indicating severe dependence. This prevalence is markedly higher than that found previously in a psychiatric sample in India [15]. One difference with this previous study was that it included patients with less common disorders, such as schizophrenia and bipolar affective disorder. Although these disorders were not examined in isolation, internet addiction may be lower in prevalence in these groups, therefore attenuating the overall prevalence. One possibility is that disordered thought and deficits in cognitive functioning that are characteristic of these disorders might inhibit the sustained engagement in internetrelated behaviours $[21,22]$. Another contributor to the high prevalence observed in the current study, relative to previous research, may be the fast-paced growth of communication devices and the accessibility of internet services in India. This might may also have led to higher proportions of excessive, maladaptive use, which is reflected in clinical samples also. The sample was also predominantly male, and rates of internet addiction are typically found to be higher amongst this sex $[8,10]$.

More broadly, the observed prevalence rates are substantially higher than those in the Indian general population and college population [8-11]. This supports previous research regarding the link between excessive internet use and poor mental health $[4,5]$. No association was observed between severity of internet addiction and the severity of illness. This is suggestive that whatever factors are attributable to excessive and problematic internet use among those with mental health disorders, once clinical thresholds have been met there may be no doseresponse relationship. However, one exception was that higher severity of illness was associated with less problematic online gaming. This may be explained by the fact that online gaming is demanding in terms of executive functioning and processing speed, which is relatively more 
impaired as illness severity increases $[23,24]$. In contrast, use of the internet and Facebook can be more easily self-regulated, and may not be as demanding on executive functioning.

The participants reported perceiving negative impacts of internet use on a range of areas, including social (reduced interaction), physical (e.g., pain), and work functioning (reduced productivity and absenteeism). In particular, most of the participants reported that internet use reduced their sleep-time. This might be particular pernicious in the context of pre-existing mental health disorders, which are often typified by reduced sleep, fatigue, and low motivation. Further sleep disturbance caused by internet use may exacerbate pre-existing sleep disorders, impact on daytime functioning, inhibit psychosocial recovery, and worsen psychiatric morbidity $[25,26]$. Interestingly, the perceived problematic impacts of internet use overlapped considerably with the reasons and perceived benefits. For example, participants noted reasons, benefits, and problems in areas such as social interaction, increased number of friends, academic pursuit, and the facilitation of schoolwork.

Kardefelt-Winther [27] proposes that internet addiction be viewed from a compensatory perspective, whereby internet use is used as form of escapism or to fulfil needs such as socialising or achievement that might otherwise be lacking in their life. From a clinical perspective, internet use may have adaptive purposes in one respect, but also serve to maintain some pathological processes through increased avoidance, a restricted range of behaviours, or a reduction in behavioural activation. When considering the perceived problems and benefits of internet use in the current study, it appears that using the internet was, on one hand, seen as helpful in areas such as leading to increased numbers of friends and helping with school, but also perceived as impacting adversely on these areas. As an example, the internet may provide access to a broader number of social opportunities, however, the quality or duration of social interactions may be limited relative to offline interaction or may be adversely affected by time spent on other online activities. Social isolation and loneliness are common features of mental health disorders, and in internet dependence also $[28,29]$. These findings indicate that internet use is perceived as having the potential to provide a means of reducing this, but may in fact serve to maintain social dysfunction, and especially in the case of excessive use and dependence. Similarly, in the case of school productivity, the internet was observed to be a good source of information and contributor to completing schoolwork, but also identified by many as reducing overall productivity, and even causing absenteeism.

The implications of this study are that excessive and problematic internet, facebook, and online gaming addictions are prevalent among psychiatric patients, and that greater detection of these co-morbid issues is indicated through systematic screening. Research shows that current treatments for internet addiction produce large and sustained effects in reducing symptoms of internet addiction, overall time spent online, and co-morbid depression and anxiety [30]. Such targeted interventions may be be particularly important in the context of psychosocial recovery. Indeed, patients who are severely dependent on internet use may not have developed or maintained the adaptive behaviours required to engage effectively with the world in other ways. However, to date no studies have evaluated culturally-relevant and appropriate interventions for internet addiction among the Indian population. Culturally-adapted interventions produce larger effects than those that are not culturally-adapted and can be four times as effective if targeted to a specific cultural group [31]. Given this, development of treatments for internet addiction in the Indian population, and particularly in Indian psychiatric populations, are indicated.
The current study was limited by recruitment from only one source, and the exclusion of some psychiatric populations, such as psychotic and bipolar disorders. Personality disorders were also not assessed, and may be a contributing factor in prevalence rates [6]. Future studies may sample a larger number of help-seeking individuals. They may also focus in on particular sub-populations, such as depressive disorders for which evidence was observed in the current study and previous samples of particularly high prevalence [7]. As noted, the predominance of men in the sample may have skewed the prevalence rates $[8,10]$. Atlhough this cannot alone account for the substantially higher numbers, future studies may seek a more balanced representation of sex. We did attempt to reduce self-selection bias, but potentially the study was participated in by individuals who were highly motivated to communicate their difficulties. The number of individuals that declined to participant was not recorded, and this limits interpretation of how representative the sample was, or which factors might have affected this. Regarding the motivations and outcomes of internet use, future research may adopt ecological momentary assessment approaches to assess these. Further, this approach might disentangle how internet use might exacerbate, maintain, or potentially mitigate in some ways the symptoms of mental health disorders, and affect psychosocial functioning more broadly [32].

In conclusion, high rates of internet addiction are found among help-seeking Indian patients with mental health disorders. The use of screening, and development of culturally-adapted treatments may be indicated in particular for this context.

\section{References}

1. Telecom Regulatory Authority of India (2017) The Indian Telecom Services Performance Indicators. New Delhi.

2. Chakraborty K, Basu D, Kumar KV (2010) Internet addiction: consensus, controversies, and the way ahead. East Asian Arch Psychiatry 20: 123-132. [Crossref]

3. Cheng C, Li AYL (2014) Internet addiction prevalence and quality of (real) life: meta-analysis of 31 nations across seven world regions. Cyberpsychol Behav Soc Netw 17: 755-760. [Crossref]

4. Carli V, Durkee T, Wasserman D, Hadlaczky G, Despalins R, et al. (2013) The association between pathological internet use and comorbid psychopathology: a systematic review. Psychopathology, 46: 1-13.

5. Ho RC, Zhang MW, Tsang TY, Toh AH, Pan F, et al. (2014) The association between internet addiction and psychiatric co-morbidity: a meta-analysis. BMC psychiatry 14 : 183. [Crossref]

6. Wildt, Bert Theodor Te, Toni Steinbuchel, Jan Dieris-Hirche, Laura Bottel, et al (2017) OP-113: Co-morbid personality disorders in patients with internet addiction." Journal of Behavioral Addictions 6: 54

7. Dieris-Hirche J, Bottel L, Bielefeld M, Steinbu"chel T, Kehyayan A, et al. (2017) Media use and Internet addiction in adult depression: A case-control study. Computers in Human Behavior 68: 96-103.

8. Sharma MK, Rao GN, Benegal V, Thennarasu K, Thomas D (2017) Technology addiction survey: An emerging concern for raising awareness and promotion of healthy use of technology. Indian J Psychol Med 39: 495-499. [Crossref]

9. Yadav P, Banwari G, Parmar C, Maniar R (2013) Internet addiction and its correlates among high school students: A preliminary study from Ahmedabad, India. Asian $J$ Psychiatr 6: 500-505. [Crossref]

10. Vyjayanthi S, Makharam S, Afraz M, Gajrekar S (2014) Gender differences in the prevalence and features of internet addiction among Indian college students. Medica Innovatica 3: 65-70.

11. Krishnamurthy S, Chetlapalli SK (2015) Internet addiction: Prevalence and risk factors: A cross-sectional study among college students in Bengaluru, the Silicon Valley of India. Indian J Public Health 59: 115-121. [Crossref]

12. Goel D, Subramanyam A, Kamath R (2013) A study on the prevalence of internet addiction and its association with psychopathology in Indian adolescents. Indian $J$ Psychiatry 55: 140-143. [Crossref] 
13. Gedam SR, Shivji IA, Goyal A, Modi L, Ghosh S (2016) Comparison of internet addiction, pattern and psychopathology between medical and dental students. Asian J Psychiatr 22: 105-110. [Crossref]

14. Sharma, Manoj K S, Ragesh G, Palanichamy TS, Hamza A, et al. (2018) Internet addiction with coexisting psychiatric diagnosis. Ind Psychiatry J 26: 243-244. [Crossref]

15. Das A, Sharma MK, Thamilselvan P, Marimuthu P (2017) Technology addiction among treatment seekers for psychological problems: Implication for screening in mental health setting. Indian J Psychol Med 39: 21-27. [Crossref]

16. Ryan T, Chester A2, Reece J, Xenos S (2014) The uses and abuses of Facebook: A review of Facebook addiction. $J$ Behav Addict 3: 133-148. [Crossref]

17. Pápay O, Urbán R, Griffiths MD, Nagygyörgy K, Farkas J, et al. (2013) Psychometric properties of the problematic online gaming questionnaire short-form and prevalence of problematic online gaming in a national sample of adolescents. Cyberpsychol Behav Soc Netw 16: 340-348. [Crossref]

18. Young KS (1998) Internet addiction: The emergence of a new clinical disorder. Cyberpsychology \& Behavior 1: 237-244.

19. Widyanto L, McMurran M (2004) The psychometric properties of the internet addiction test. Cyberpsychol Behav 7: 443-450. [Crossref]

20. Andreassen CS, Torsheim T, Brunborg GS, Pallesen S (2012) Development of a Facebook Addiction Scale. Psychol Rep 110: 501-517. [Crossref]

21. Heinrichs RW, Zakzanis KK (1998) Neurocognitive deficit in schizophrenia: a quantitative review of the evidence. Neuropsychology 12: 426-445. [Crossref]

22. Torres IJ, Boudreau VG, Yatham LN (2007) Neuropsychological functioning in euthymic bipolar disorder: a meta-analysis. Acta Psychiatr Scand Suppl 116: 17-26. [Crossref]
23. McDermott LM, Ebmeier KP (2009) A meta-analysis of depression severity and cognitive function. $J$ Affect Disord 119: 1-8. [Crossref]

24. Stavro K, Pelletier J, Potvin S (2013) Widespread and sustained cognitive deficits in alcoholism: a meta-analysis. Addict Biol 18: 203-213. [Crossref]

25. Fernández-Mendoza J, Vela-Bueno A, Vgontzas AN, Olavarrieta-Bernardino S, Ramos-Platón MJ, et al. (2009) Nighttime sleep and daytime functioning correlates of the insomnia complaint in young adults. $J$ Adolesc 32: 1059-1074. [Crossref]

26. Ford DE, Kamerow DB (1989) Epidemiologic study of sleep disturbances and psychiatric disorders. An opportunity for prevention? JAMA 262: 1479-1484. [Crossref]

27. Kardefelt-Winther D (2014) A conceptual and methodological critique of internet addiction research: Towards a model of compensatory internet use. Computers in Human Behavior 31: 351-354.

28. Meltzer H, Bebbington P, Dennis MS, Jenkins R, McManus S, et al. (2013) Feeling of loneliness among adults with mental disorder. Soc Psychiatry Psychiatr Epidemiol 48: 5-13. [Crossref]

29. Nalwa K, Anand AP (2003) Internet addiction in students: a cause of concern Cyberpsychol Behav 6: 653-656. [Crossref]

30. Winkler A, Dörsing B, Rief W, Shen Y, Glombiewski JA (2013) Treatment of internet addiction: a meta-analysis. Clin Psychol Rev 33: 317-329. [Crossref]

31. Griner D, Smith TB (2006) Culturally adapted mental health intervention: A metaanalytic review. Psychotherapy: Theory, research, practice, training. 43: 531

32. Shiffman S, Stone AA, Hufford MR (2008) Ecological momentary assessment. Annu Rev Clin Psychol 4: 1-32. [Crossref]

Copyright: (C2019 Nisbin AK. This is an open-access article distributed under the terms of the Creative Commons Attribution License, which permits unrestricted use, distribution, and reproduction in any medium, provided the original author and source are credited. 